\title{
Obstructive uropathy associated with primary ureteral endometrioma: case report and review of the literature
}

\author{
Andrew Feifer, MD; Mona Alam El-Din, MD; Atilla Omeroglu, MD; Maurice Anidjar, MD
}

\begin{abstract}
We report the case of a 56-year-old postmenopausal woman who presented with incidental left hydronephrosis during an investigation for a gastrointestinal complaint. The patient denied any history of flank pain or hematuria. Contrast-enhanced computed tomography revealed severe right-sided ureterohydronephrosis as well as renal atrophy. The contralateral kidney was normal, as was the patient's overall renal function. A retrograde ureterogram demonstrated complete ureteral obstruction $4 \mathrm{~cm}$ proximal to the ureterovesical junction. Subsequent ureteroscopy revealed a polypoid mass completely occupying the ureteral lumen, of which the biopsies demonstrated inconclusive atypical urothelial changes. The patient underwent a laparoscopic nephrectomy with open dissection of the distal ureter. The patient recovered well postoperatively. Final pathology revealed a benign obstructing endometrioma without evidence of invasion from periureteral tissue. This appears to be the first reported case of asymptomatic primary ureteral endometrioma with secondary renal atrophy. Earlier investigation and treatment may have allowed for renal preservation earlier in the course of the disease.
\end{abstract}

Can Urol Assoc J 2009;3(3):E10-E13

\section{Résumé}

Nous décrivons le cas d'une femme ménopausée de 56 ans présentant une hydronéphrose gauche découverte de façon fortuite au cours d'un examen mené pour donner suite à des symptômes gastro-intestinaux. La patiente n'avait pas d'antécédents de douleur au flanc ou d'hématurie. Une TDM avec agent de contraste a révélé une urétéro-hydronéphrose droite importante accompagnée d'une atrophie rénale. Le rein controlatéral et la fonction rénale globale de la patiente ne présentaient aucune anomalie. Une urétérographie par voie rétrograde a permis d'observer une obstruction complète de l'uretère proximale à $4 \mathrm{~cm}$ de la jonction urétérovésicale. Une urétéroscopie subséquente a révélé une masse polypoïde occupant la totalité de la lumière urétérale et des analyses après biopsie ont montré des changements atypiques non concluants au niveau de l'épithélium urinaire. La patiente a subi une néphrectomie par laparoscopie avec dissection ouverte de l'uretère distale. La patiente s'est bien rétablie après l'intervention. Le rapport final de pathologie a révélé un endométriome obstructif bénin sans signe d'invasion des tissus péri-urétéraux. II semble que ce soit ici le premier cas signalé d'endométriome urétéral primitif asymptomatique avec atrophie rénale secondaire. Un examen et un traitement réalisés plus tôt dans le cours de l'évolution de la maladie auraient pu permettre la préservation du rein.

ctopic endometrial tissue growth is generally benign with the clinical course characterized by local aggressiveness to all pelvic organs, secondary pelvic pain and secondary infertility. Involvement of the urinary tract, specifically ureteral involvement, is rare, but when present can cause significant morbidity and necessitates prompt diagnosis and treatment in order to preserve renal function.

A 55-year-old woman presented to the emergency department at one of the McGill University Health Centre's teaching hospitals for evaluation of an acute abdominal pain. On presentation the patient was hemodynamically normal and aseptic, but appeared to be in acute distress. The nature of the pain was diffuse and nonspecific. Although the symptom review, physical examination and biochemistry did not reveal any specific focal abnormality to explain the symptoms, the patient was further evaluated by abdominal sonography to rule out biliary tract disease. Most notably, the patient denied any genitourinary complaints, including hematuria, flank pain or any other irritative or obstructive lower urinary tract symptom.

The patient's medical history was significant for a total abdominal hysterectomy for the treatment of severe dysfunctional uterine bleeding and a large benign ovarian mass. The procedure was uncomplicated, and the patient recovered quickly and without incident. Histopathological diagnosis after the procedure revealed a left dermoid ovarian cyst (benign cystic teratoma) and multiple uterine leiomyomas as well as an endometrial polyp and adenomyosis. Years after this procedure, and secondary to a strong family history of breast carcinoma, the patient was placed on a regimen of the selective estrogen receptor modifier tamoxifen $(20 \mathrm{mg} / \mathrm{d}$ for $5 \mathrm{yr}$ ) as part of a prevention protocol strictly for breast cancer risk modification, and not for the presence of any known recurrent gynecological condition. This medication was tolerated well by the patient, and she did 
not report any untoward side effects for the duration of her treatment ( $5 \mathrm{yr})$.

Ultrasonography completed for her current presentation revealed normal pelvic and biliary anatomy; however, it did incidentally reveal a severe right hydroureteronephrosis with evidence of cortical atrophy and pyelectesis. The further urological investigation that ensued included a normal cystoscopy, and a retrograde ureterogram, which revealed complete distal obstruction $3-4 \mathrm{~cm}$ proximal to the ureterovesical junction with a marked intraluminal filling defect (Fig. 1). Contrast-enhanced computed tomography was obtained, which confirmed the right hydronephrosis and renal cortical thinning $(4 \mathrm{~mm})$. The right kidney and bladder appeared normal, and there was no identifiable pelvic mass. Contrast excretion from the effected side was not demonstrated. For the purposes of tissue diagnosis, a right ureteroscopy was performed in the standard fashion using a semirigid ueteroscope. A "sausageshaped" soft tissue mass occupying the entire ureteral lumen was visualized, and it did not display the typical features associated with transitional cell carcinoma. Further safe ureteral evaluation was abandoned secondary to the inability to pass guidewires proximally. A cold-cut biopsy was taken and sent for pathological evaluation. Results of the biopsy were unfortunately deemed inconclusive, and after appropriate consultation and further imaging to confirm the kidney was nonfunctional, a decision was made to proceed with a laparoscopic nephroureterectomy.

\section{Pathological findings}

Gross examination of the right nephroureterectomy specimen showed an enlarged kidney measuring $10 \times 6 \times 4 \mathrm{~cm}$ attached to the ureter. The ureter was $12 \mathrm{~cm}$ long with an average diameter of $1 \mathrm{~cm}$. The cut section of the kidney revealed thinning of the renal parenchyma and cortical atrophy with only a thin rim of parenchyma (Fig. 2). The renal pelvis and calyces were cystically dilated. The lower third of the ureter carried a $4 \times 2 \times 1-\mathrm{cm}$ polyp, reddish-white in colour with glistening surface. The polyp was situated $2.5 \mathrm{~cm}$ from the distal end of the ureter.

Microscopic examination of the specimen revealed an endometrial polyp, covered with normal urothelium from the ureter. The polyp showed positive immunoreactivity to estrogen receptors (Fig. 3). The kidney showed end-stage renal atrophic changes (Fig. 4).

\section{Discussion}

Ectopic endometrial tissue growth is generally benign and clinical course characterized by local aggressiveness to all pelvic organs, secondary pelvic pain and secondary infertility. Clinical diagnosis is based on history, physical examination and often evidence of disease during exploratory laparoscopy. It affects women of premonopausal age in the range of $10 \%-20 \% .^{1,2}$

Involvement of the urinary tract at the vesical, ureteral or renal level ranges between $1 \%$ and $11 \%$ in a ratio of 40:5:1. ${ }^{3}$ This represents an overall rate of genitourinary involvement of $1 \%-2 \%$ of all cases. ${ }^{4-7}$ Other documented sites of endometriosis involvement include the gastrointestinal tract, lungs, pelvic lymph nodes, umbilicus, extremities, vulva, and laparotomy or episiotomy scars. ${ }^{8-11}$

Ureteral involvement is rare, but when present can cause significant morbidity, and necessitates prompt diagnosis and treatment in order to preserve renal function. It unusually presents with nonspecific symptomatology, and can present as a significant diagnostic dilemma. Ureteral involvement is typically secondary to extrinsic compression or ingrowth of endometrial tissue, occasionally presenting as an infiltrating luminal mass. Occasionally, incidental involvement of the genitourinary system in an otherwise asymptomatic patient is possible.

To our knowledge, this represents the first reported case of a primary ureteral endometrioma. Prior characterization of this phenomenon includes only 1 study describing endometrial polyoposis of the pelvic peritoneal reflection. This report attributed the finding to a rebound withdrawal phenomenon on withdrawal of gonadotrophin-releasing hormone agonist, used to treat severe pelvic endometriosis. ${ }^{12}$

In our case, the occurrence of the ectopic endometrial polyp in the ureter might be explained by a transformation

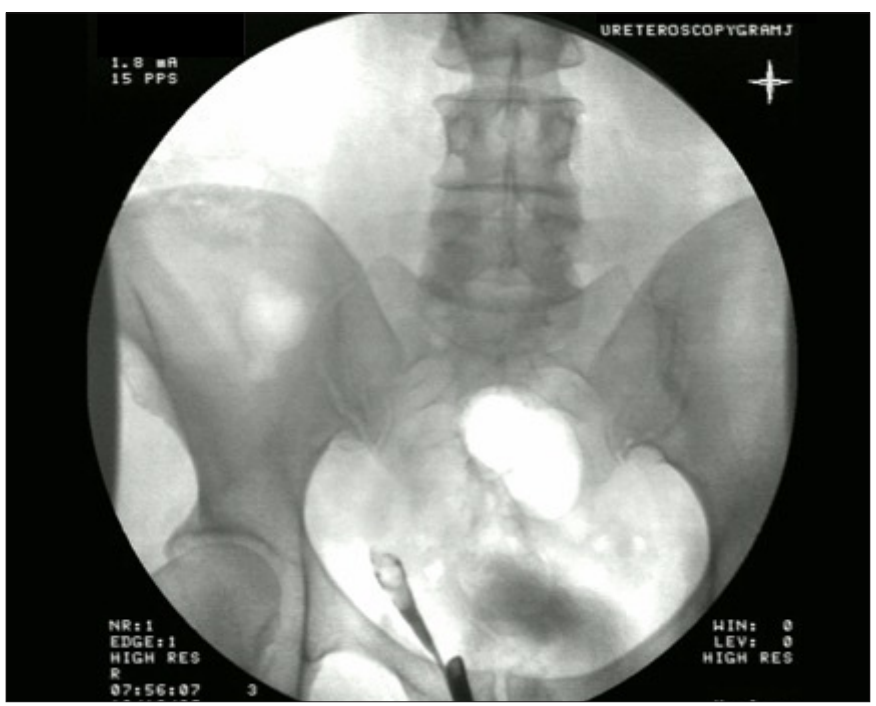

Fig. 1. Right retrograde pyelogram demonstrating large filling defect in the distal right ureter. 
of a previous ureteral endometriosis into an endometrial polyp. This is supported by evidence from series documenting endometrial polyp detection in $50 \%$ of the patients with endometriosis. ${ }^{13}$ This is further supported by studies documenting the presence of ureteral endometriosis in $1 \%-5 \%$ of women with pelvic endometrial implants. ${ }^{5}$

The patient's history of tamoxifen use adds an interesting dimension to this case. It has been previously demonstrated that tamoxifen is associated with a 3 to 4-times higher incidence of adenomyosis ${ }^{14}$ among postmenopausal breast cancer patients, and a strong association with endometrial polyps was similarly established. ${ }^{15}$ It seems plausible that the use of tamoxifen by our patient might have contributed, and, further, might have been solely responsible for the

development of her adenomyosis and ureteral endometrial polyp. It is also possible that subclinical ureteral endometriosis might have been transformed into the obstructive ureteral polyp. The growth of the polyp years after her previous diagnosis of adenomyosis is in keeping with the findings of reported studies that urinary tract endometriosis can be either synchronized with pelvic endometriosis or might appear later, with an average latency period of 3 years. ${ }^{16}$ It is, however, noteworthy that the actual nephroureterectomy specimen contained no histopathological evidence of endometriosis. This raises the prospect of a de novo endometrial ureteral polyp from an embryological remnant.

Endometrial involvement of the urinary tract is a rare
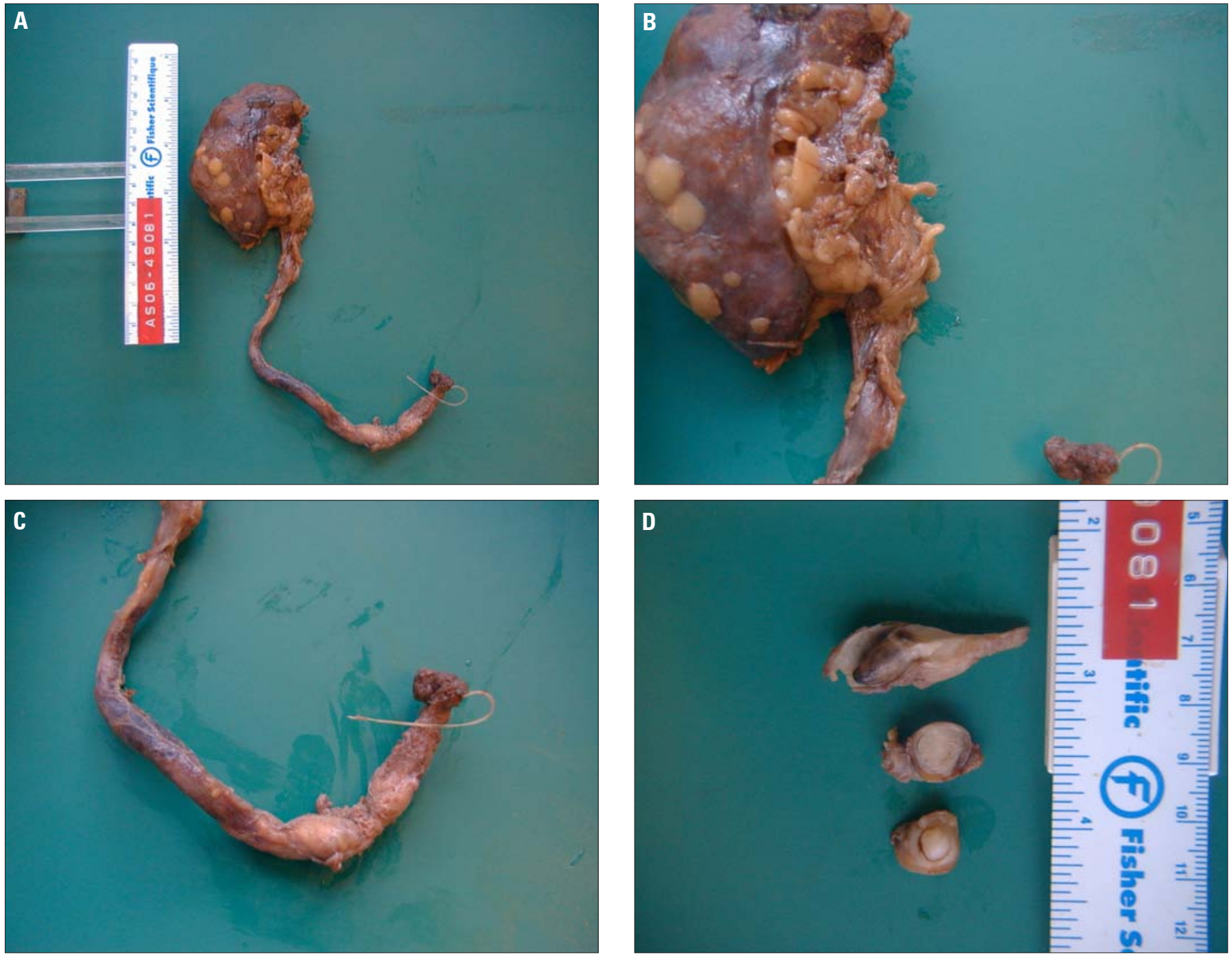

Fig. 2. The kidney with advanced hydronephrosis in which there is only a thin rim of remaining renal cortex (A, B). The lower end of the ureter carries a glistening reddish-white polyp (C, D). 

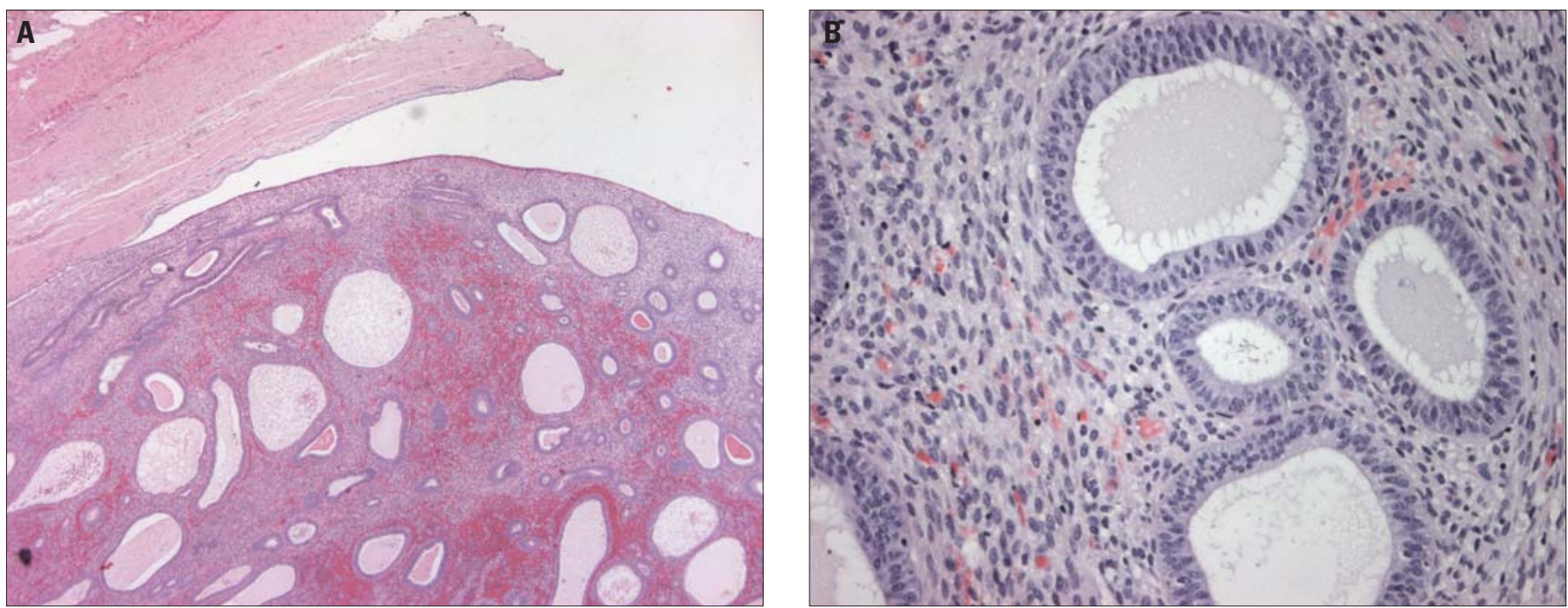

Fig. 3. Microscopic examination of the specimen revealed an endometrial polyp, covered with normal urothelium from the ureter (A). The polyp showed positive immunoreactivity to estrogen receptors (B). Hematoxylin-eosin stain, original magnification $\times 10(A)$ and $\times 200$ (B).

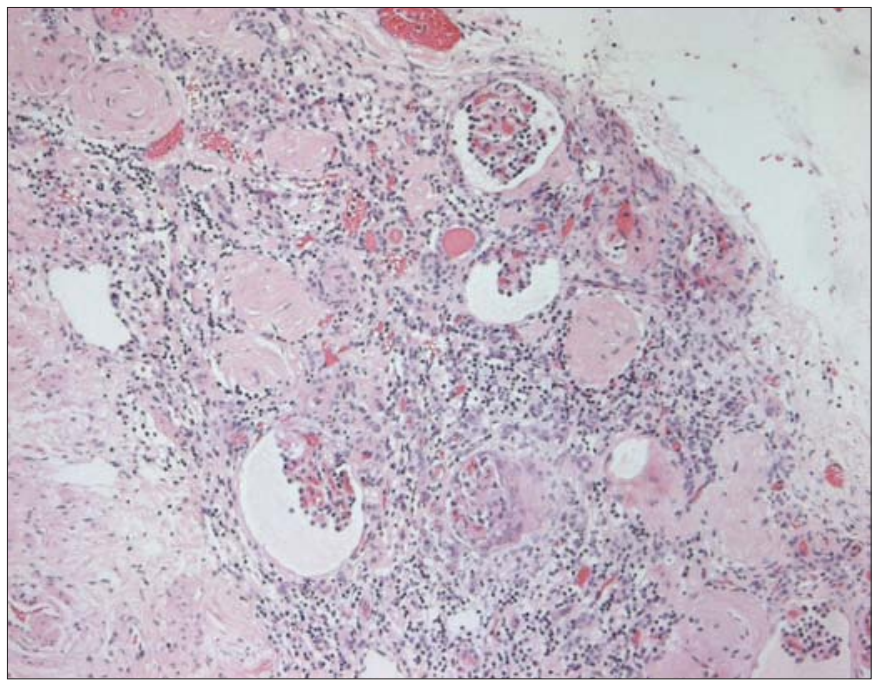

Fig. 4. The kidney showing marked parenchymal atrophy (end-stage renal disease). Hematoxylin-eosin stain, original magnification $\times 10$.

event. However, when this occurs, prompt diagnosis and management are crucial in order to prevent significant morbidity. Therefore, some studies recommend an upper urinary tract evaluation for all patients diagnosed with pelvic endometriosis to exclude any obstructive process. ${ }^{17,2}$

Division of Urology and Department of Anatomical Pathology, McGill University Health Centre, Montréal, Que.

This article has been peer reviewed.

Competing interests: None declared.

\section{References}

1. Jubanyik KJ, Comite F. Extrapelvic endometriosis. Obstet Gynecol Clin North Am 1997;24:411-40.

2. Vessey MP, Villard-Makintosh L, Painter R. Epidemiology of endometriosis in women attending family planning clinics. BMJ 1993;306:182-4.

3. Antonelli A, Simeone C, Frego E, et al. Surgical treatment of ureteral obstruction from endometriosis: our experience with thirteen cases. Int Urogynecol J Pelvic Floor Dysfunct. 2004;15:407-12.

4. Ball TL, Platt MA. Urologic complications of endometriosis. Am J Obstet Gynecol 1962;84:1516-21.

5. Denes FT, Pompeo ACL, Momtellato NID. Ureteral endometriosis. Int Urol Nephrol 1980;12:205-9.

6. Dick AL, Lang DW, Bergman RT. Postmenopausal endometriosis with ureteral obstruction. Br J Urol 1973:45:153-5.

7. Stanley KE, Utz DC, Dockerty MB. Clinically significant endometriosis of the urinary tract. Surg Gynecol Obstet 1965;120:491-5.

8. Beischer NO. Endometriosis of an episiotomy scar cured by pregnancy. Obstet Gynecol 1966;28:15-21.

9. Paull T, Tedeschi LG. Perineal endometriosis at the site of episiotomy scar. Obstet Gynecol 1972;40:28-34.

10. Shook TE, Nyberg LM. Endometriosis of the urinary tract. Urology 1988;31:1-6.

11. Terada $Y$, Chen F, Shoji T, et al. A case of endobronchial endometriosis treated by subsegmentectomy. Chest 1999;115:1475-8.

12. Othman NH, Othman MS, Ismail A. N., et al. Multiple polypoid endometriosis-a rare complication following withdrawal of gonadotrophin releasing hormone (GnRH) agonist for severe endometriosis: a case report. Aust N Z J Obstet Gynaecol 1996;36:216-8.

13. Kim MR, Kim YA, Jo MY, et al. High frequency of endometrial polyps in endometriosis. J Am Assoc Gynecol Laparosc 2003; 10:46-8.

14. Cohen I, Beyth Y, Tepper R, et al. Adenomyosis in postmenopausal breast cancer patients treated with tamoxifen: a new entity? Gynecol Oncol 1995;58:86-91.

15. Cohen I. Endometrial pathologies associated with postmenopausal tamoxifen treatment. Gynecol Oncol 2004:94:256-66.

16. Antonelli A, Simeone C, Zani D, et al. Clinical aspects and surgical treatment of urinary tract endometriosis: our experience with 31 cases. Eur Urol 2006;49:1093-7.

17. Stillwell TJ, Kramer SA, Lee RA. Endometriosis of ureter. Urology 1986;28:81-5.

Correspondence: Dr. Andrew Feifer, Senior Resident, Division of Urology, McGill University Health Centre, 4065 Gage St., Montréal QC H3Y IR6; fax 514 843-1552; drafeifer@gmail.com 